

\title{
Passionate forms and the problem of subjectivity: Freud, Frau Emmy von N. and the unconscious communication of affect
}

\author{
Jan Campbell and Steve Pile* \\ Department of Geography, The Open University, Walton Hall, Milton Keynes, \\ MK7 6AA, United Kingdom. \\ E-mail: s.j.pile@open.ac.uk \\ *Corresponding author.
}

\begin{abstract}
This article considers the transfer and circulation of affects in Freud's first clinical case, 'Emmy Von N.' We are especially concerned to tease out the unconscious communication of affects within Freud's case study. In part, this is to contribute to an understanding of the relationship between affect and its representative, passionate, forms. In part, our close reading of the case study is also designed to contribute the recent debates about 'the problem of subjectivity'. In our reading of the course of Emmy's treatment and Freud's therapeutic interventions, we disclose the unconscious communication between them, especially involving the transfer of affects - with Emmy insisting on their passionate nature and Freud's attempts to undermine her passions. We argue that it is precisely through appreciating the unconscious exchange of affects and their passionate forms that Freud came to understand the possibility of new forms for those passions.
\end{abstract}

Keywords: affect; transference; unconscious communication; Freud; Emmy von $\mathrm{N}$; passionate forms

\section{Introduction: Affect, the Problem of Subjectivity, and a Case of Hysteria}

In her recent book, Immaterial Bodies, Lisa Blackman situates the so-called 'affect turn' in the social sciences within a longer set of concerns about, what we can call, the problem of subjectivity (see 2012, pp. 21-25). Although the 'affect turn' is comprised of many strands, many of which criss-cross and 
entwine, Blackman identifies one particular thread that winds around the idea of a 'subjectless subject' (2012, pp. 74-76). Accordingly, affect is understood as not requiring a subject, but rather it emerges between bodies and is registered in bodies (following Massumi, 2002; see also Clough, 2010). In particular, Massumi (2002) argues that affect and emotion 'follow different logics and pertain to different orders' (p. 27). Although seemingly personal, emotions are actualized through language and culture into social circuits of action and meaning. On the other hand, affects are virtual, both unrepresented and also a set of possibilities (2002, p. 30). These virtual possibilities are closed down when affect becomes consciously perceived and represented. Thus, once subjects become aware of affect, they convert it into language, as 'expressed emotions', which is both inadequate and also forecloses on the possibilities of affect. Such a view challenges, as Blackman observes, the idea of a coherent integrated rational self-aware subject - as subjects are constituted through the emergence of affect that they only belatedly become aware of. As importantly, affect is registered in the body neurologically before cognition (see Leys, 2011). Where the body is lively, dynamic, open and dynamic, consciousness forecloses, labels, structures, renders dull and tames the subject. There is a clear separation, in this position, between affect and emotion, between the un-expressed and the expressed, between the non-conscious and the conscious. Boldly, we can say that the 'subjectless subject' is pre-social and non-psychological (see also Hemmings, 2005). This view is contested by those seeking a constitutive role for language and discourse in the production of subjectivity.

Wetherell (2012), in her thorough book-length review of the recent literature on affect and emotion, provides a critical assessment of the 'subjectless subject' position (pp. 19-20). For her, the dichotomy between affect and emotion cannot appreciate how it is that affects come to be represented, especially in discourse. She sets out an alternative position on the problem of subjectivity, which we might call the 'social subject'. In this account, subjects take up positions in relation to the social through their adoption of discourse, primarily through language. Rather than affect being impoverished or foreclosed by its representation in language, Wetherell sees language as an affective practice. Thus, language becomes a carrier for affect, enabling it to be shared between subjects as well as understood inter-subjectively. Not only are subjects constituted through the movement of affect between subjects, inter-subjectively, they are also interpolated into social grids of meaning and power. As people grow up, they pick up more than overt social etiquettes, rules and laws, they also inhabit more tacit forms of sociability, such as attitudes, values and norms. Feelings, affects, emotions may appear inchoate and inexpressible, yet through 'structures of feeling', through practices, and through social and cultural repertoires, feelings, affects and emotions are given shape and form. As much as language, these are registered in the body through deportments, demeanours, manners and the like. This account draws widely on thinkers as diverse as Williams (1958), Bourdieu (1984) and 
Goffman (1981). Boldly, we can say that the subject is social, yet also nonpsychological.

What the 'subjectless subject' offers is a way of appreciating the non-conscious forces that emerge in bodies and through bodies, while the 'social subject' provides a way to understand how subjects are formed through inter-subjective relationships and social practices, especially language. Yet, there is a sense in which the relationship between affect, its circulation and emergence in bodies, and its representation remains a problem - the latest iteration of the problem of subjectivity. The problem rests, on the one hand, on the question of the transfer of affect between subjects, and, on the other, on the understanding of the relationship between the body, affect and its representative forms.

Blackman's own solution explicitly seeks a post-psychological solution to the problem of psychologizing the subject. She invokes the idea of threshold phenomenon as a way to think about the space between affect and emotion in the production of subjectivities. Phenomena such as hearing voices or hypnosis are vital instances of the relationship between the body, the movement of affect, expressed emotions and the social. In this way, she seeks to entwine - and unravel - subjects in bodily, non-conscious, conscious and social processes. We are similarly interested in threshold phenomena. In particular, however, we wish to think through how affects and emotions are communicated between subjects and take on, what we will call, passionate forms (see Campbell, 2013). For us, passionate forms are, like Blackman's threshold phenomena, grounded in the body, in non- and un- conscious processes, in consciousness, and in the social and its worlds. Thus, our emphasise in this article is on how passionate forms emerge not only from within the psychological and non-psychological imperatives of the subject, but also between the subject and the world - in this case, between the patient and her doctor: our chosen example is one of Freud's pre-psychoanalytic case studies of hysteria.

What we seek to offer is not only a psychological subject that has nonconscious affects and expressed emotions, but also a way to follow the devious means through which affects find their passionate forms. For us, this is not simply a conceptual argument: being able to re-connect - to close the distance between affects and emotions can be thought of as a central aim for therapeutic practice, for it is this that enables the movement of affects in the search for new passionate forms.

In keeping with the idea that therapy involves the search for new forms for our passions, we have selected a case study where the doctor and the patient embark on an arduous and often frustrating search for new passionate forms (as we hope to convey in the course of the article). The patient is Frau Emmy von N. and the doctor is Sigmund Freud (Freud, 1895a). What we will emphasize in our reading of this case study will be, first, how affects are registered in the body of the patient; second, that the gap between emotions and affects cannot be closed simply by assuming that the words-for-affects refer to the affects themselves; and, finally, that affects emerge between the patient and the doctor, unconsciously, 
through the body through passionate forms. In this model, this transfer of affects is not pre-social nor non-social, yet nor can affects be transmogrified into questions of sociability or of discourse. In this model, the subject is psychological, yet not in a way that presumes a coherent, rational, self-aware subject. Such a model parallels work that insists on the significance of thought transference in Freud's therapeutic practice (Campbell and Pile, 2010; see also Blackman, 2012, especially pp. 78-84). What this work on transference reveals is how Freud understood affects as moving between subjects unconsciously. More than this, transference highlights those aspects of the unconscious that are receptive and communicative. In part, this corrects the impression that Freud was solely concerned with the seemingly locked box of the repressed unconscious.

For us, affects - whether they are seen as emergent within the early personal self; or, on the move between people; or, as a quality that is ascribed to internal objects or to the external world - are always in search of forms through which they can find elaboration. This was the invaluable connection Freud made between the hysterical symptoms that he witnessed and the stories his hysterical patients told him. More than this, Freud was able to discern, in the forms that affects took, how affects continually search for expression, consciously and unconsciously, in the relationships subjects form with their worlds. Affects not only travel beyond the subject, they also set up lines of communication both within the self and also in relation to others (human and non-human) (see also Blackman, 2012, pp. 183-184; also, Pile, 2014). In our exploration of the movement and circulation of affect in Freud's case study of Emmy, we seek to show how this occurs - through hypnosis, suggestion and the transferential dynamics of the clinical setting - dynamically, communicatively and unconsciously.

A great deal of critical attention has been paid to Freud's treatment and analysis of Emmy: see for example Tögel, 1999; or, Bollas, 2000. Two intellectual moves are broadly typical of these critical reassessments of the Emmy case study. On the one hand, there is a move to re-situate Emmy - as Fanny Moser (née Fanny Louise von Sulzer-Wart on 29 July 1848) - in her social setting, providing a critical historical reading of the case study. In the main, Fanny's life is read through her family relationships. Commonly, accounts connect Fanny to her mother, to her husband Heinrich Moser, to Heinrich's son by another wife, Henri, and finally to her two daughters with Heinrich, Fanny and Mentona (see especially Ellenberger, 1977 [1993]; and, Appignanesi and Forrester, 2005, pp. 92-103). Importantly, Freud is as much a part of the social and historical setting as Fanny, in terms of both his medical career and also the history of central European medical practices. On the other hand, there is a clinical move that re-examines Emmy's symptoms and attempts alternative psychoanalytic interpretations. Commonly, the case study is seen as unfolding through techniques and notions that Freud will later abandon in favour of his own distinctive approach, psychoanalysis. Alongside this, there is a debate about whether the term hysteria is diagnostically or therapeutically appropriate. From this 
perspective, Freud is an ally, albeit a flawed one, in an understanding of hysterical symptoms and their treatment (see Bromberg, 2001; Goldstein, 2001; Roth, 2001; or, Schwartz, 2001). These moves are invaluable in offering insights into Freud's case study, contextually and therapeutically.

Even so, it is not our intention in this article to re-interpret Moser's familial circumstances or to re-diagnose Emmy's hysterical symptoms. Instead, our focus is upon the dynamic, multi-layered relationship between Emmy - both as patient and as Moser, then one of the wealthiest women in Europe - and Freud, then a struggling, newly married, impecunious doctor. In particular, we are interested in tracing the unconscious communication between Emmy and Freud. This is for two reasons.

First, we see unconscious communication as foundational for the theory and practice of psychoanalysis. We wish to see this case study as the beginning of psychoanalysis, rather than the end of the line for hysteria, hypnosis and suggestion in Freud's development of psychoanalysis. In fact, we would go so far as to say that Moser is very good at telling Freud how to be a (good) psychoanalyst - a lesson Freud does rather well to learn, given that he is not at all inclined to allow this particular patient to take control of the therapeutic setting.

Second, the unconscious communication between Emmy and Dr Freud, between Fanny and Sigmund, between ambitious doctor and wealthy influential client, is (of course) multi-layered, dyed with desire, fury, jealousy, dejection, rejection and revulsion. This is interesting in itself, however we would like to use Emmy's hysterical injunction, 'Keep Still! - Don't Say Anything! - Don't Touch Me!', to draw out different aspects of unconscious communication. Classically, unconscious communication is viewed almost like a radio message from a spy reporting from behind enemy lines: the patient covertly transmits coded messages, the analyst secretly receives them, albeit at first uncomprehendingly. Yet, through talking patient and analyst can decode these secret communiqués and bring them into the open, such that repressed thoughts and ideas can be talked about and worked through. So it is of vital interest that one part of Emmy's protective formula is the injunction not to say anything. For us, bringing things into representation the requirement in analysis to say something - is about more than how affects get represented in words, it is also a question of how affects travel (see, for example, Pile, 2010a; and, Campbell and Pile, 2011): that is, about how passionate forms form, move, meet, engage and entwine - through the body and its worlds.

\section{Three Weeks in Vienna: Dr Freud in the Service of Fanny Moser and Frau Emmy von $\mathrm{N}$}

'On May 1, 1889', Freud(1895a) writes, 'I became the doctor of a lady of about forty years of age' (p. 51). In the case study, she goes by the pseudonym Frau 
Emmy, but we now know her to have been Moser. She was a long-time sufferer from a wide range of hysterical symptoms. The historian Henri Ellenberger surmises that Josef Breuer probably referred Frau Moser to Dr Freud. Not only was Freud not her first choice of doctor, he was the latest in a long line of doctors who had treated, or cared for, Fanny. Fanny herself was a controversial figure: not only had she married a much older man, Heinrich was 65 while she was 23, 4 years after his death a rumour also spread that she had poisoned him (probably propagated by Heinrich's son, Henri). Controversial or not, Heinrich left Fanny extremely rich. Despite her wealth, Fanny was treated as an outsider by aristocratic society. Even so, Frau Moser created a social circle around her that included poets, geologists, neuropsychiatrists and philosophers. Ellenberger reports:

she gave the impression of a mixture of dignity and eccentricity and that she was excessively touchy. She had admirers and lovers, including among the latter, it was said, several of her doctors. She tried to keep these relationships secret, but her daughters and her immediate circle knew about them

(1977, p. 282, emphasis added)

Freud gives no indication in his case study that his patient had a dubious reputation or that she is in a position of enough wealth and influence to make or break his career. Instead, Freud (1895a) emphasizes how impressed he is by her, including, significantly, her susceptibility to hypnosis: 'she was a hysteric who could easily be set into a state of somnambulism' (p. 51). After Breuer's success with Anna O, Freud was intent on using his method to address his new patient's symptoms, despite feeling that he had not yet fully mastered the technique of hypnosis and suggestion.

Freud's first notes on Emmy are illuminating. It is worth quoting at length:

May 1, 1889. I find a woman who has distinctive, finely cut features and an appearance that is still youthful lying on the couch with a leathery bolster under her neck. Her face bears a tense, pained expression; her eyes are screwed up and cast down; she has a heavy frown and deep naso-labial folds. She speaks as if it were arduous, in a quiet voice that is occasionally interrupted to the point of stuttering by spastic breaks in her speech. When she speaks she keeps her fingers, which exhibit a ceaseless agitation resembling athetosis, tightly interlaced. Numerous tic-like twitches in her face and neck muscles, some of which, in particular the right sternocleidomastoid, protrude quite prominently. In addition, she frequently interrupts herself in order to produce a peculiar clicking noise, which I am unable to reproduce.

$$
\text { (1895a, pp. 51-52) }
$$


Emmy is, according to Freud, highly educated and intelligent, capable of clear and coherent communication. Freud is doubly disconcerted: not only by Emmy's symptoms, but also by the contrast between the articulate Fanny and the hysterical Emmy. Thus, Freud's descriptions of Emmy alternate between the personally engaged (she is youthful; he is disconcerted; she lies on a leathery bolster), the medically trained (the resemblance of the symptoms to athetosis; her protruding sternocleidomastoid muscle), the aesthetically detached (her finely cut features), and a disturbing horror (her curious bird-like clacking; her clenched fingers).

Within the first few pages of the case study, we can already begin to discern the dynamics that will determine the course of the treatment. For us, the significant feature of the treatment is the movement to-and-fro between Freud and Emmy, as doctor and patient seek to sway each other to their intentions. Much of this toand-fro is highly charged, emotionally, yet also sometimes detached, and at other times confounding and alarming - yet, it is in such moments that we can begin to glimpse the unconscious communication of affects. Thus, Emmy can display almost passive obedience - submitting to Freud's care, allowing him to ban visits by her daughters, yet, she can also be tyrannical, devious and flirtatious. In this 'pas de deux', it is the doctor that is constantly wrong-stepped by the patient and her symptoms.

In particular, Freud is thrown by sudden interruptions in normal conversation, during which Emmy's face would contort into an expression of horror and revulsion. She would

stretch out her hand towards me with her fingers splayed and crooked, and in an altered, fearful voice call out the words: 'Keep still - don't say anything - don't touch me!

Freud ventures that Emmy must be suffering from some kind of hallucination and uses 'Keep still - don't say anything - don't touch me!' as a protective formula to fend off, what Freud presumes to be, a person: indeed, a stranger. Emmy has sent her message (through words and through the body), with its overt and covert sides, now Freud wishes to decode it; his version of the enigma machine will be hypnosis. It will not prove easy, however, for patient and doctor to work out the hidden meanings behind the message; worse, the enigma machine of hypnosis will prove, at best, unreliable and, at worst, unworkable. It will be tough going, right from the outset. Significantly, hypnosis is not the only treatment Freud applies: there is a lot more physical contact between them than you might expect, none of which is, we believe, inconsequential.

A day after they first meet, on the evening of Thursday 2 May 1889, Freud visits Emmy at the sanatorium (possibly Wilhelm Svetlin's clinic in Vienna: see Shorter, 1989). Emmy is extremely nervous, so Freud asks that doctors and nurses knock loudly on her door and wait for her to ask them to come in. 
Even so, Emmy still grimaces when people enter her room. On top of this, she has new symptoms: she feels cold and also has pains that run from the top of the hip down her right leg. Freud prescribes warm baths and, importantly, a twice-daily whole body massage, which he himself will administer. Whether he intends it or not, Freud has already committed himself to disobeying one aspect of Emmy's protective formula: 'don't touch'. And he is about to disobey another: he is going to say something - and it will be her that must be still. Freud sets about using hypnosis as a treatment for Emmy's hysteria.

From the very beginning, hypnotizing Emmy is all too easy. In their first session, Freud simply puts up a finger and exclaims 'Sleep!' Emmy sinks down, looking dazed and confused. Then, Freud uses suggestion to treat Emmy. He invites her to believe that, when she wakes up, she will find that her symptoms have completely disappeared. Emmy listens attentively as Freud attempts to implant the suggestion. He does not say how he performs suggestion, but Freud probably uses a mixture of repetition, persuasion and association to deeply embed the idea that a symptom will be cured (on the history of hypnotic therapies, see Chertok and Stengers, 1992; also, Winter, 1998). Gradually, Freud sees Emmy's expression change, becoming soft and peaceful. Yet, the first hypnotic session appears to be only partially successful. Undaunted, Freud persists.

From Friday 3 May to Tuesday 7 May, Emmy's therapeutic regimen continues. She takes warm baths and Freud carries on with the whole body massages. Twice a day, Emmy undergoes hypnosis, as Freud attempts to resolve her symptoms through suggestion. Most of the rest of the day, Emmy spends in bed. Her condition visibly improves.

On the morning of Wednesday 8 May, Emmy tells Freud about a horrid story she had just read in Frankfurter Zeitung. According to Emmy, an apprentice had been tied up and a white mouse put into his mouth. The boy died of shock. 'As she recounts this,' Freud reports,

all the signs of horror emerge in the most vivid form. She clenches and unclenches her hand several times in succession. 'Keep still, don't say anything, don't touch me! - If an animal like that were in my bed'.

In the hypnotic session in the evening of 8 May, Freud asks Emmy about why she is so easily frightened. In reply, without hesitation, Emmy rapidly recalls a series of traumatic memories from her early childhood: when she was 5 years old, dead animals were thrown at her by her brothers and sisters; at 7, she saw her sister in a coffin; when 8 , her brother dressed up as a ghost to frighten her; at 9, her dead aunt's jaw suddenly dropped open. Each recollection provokes Emmy to convulse, her face full of fear, and, at the end of the last story, her mouth opens wide and she gasps for air. Finally, she becomes peaceful. 
Afterwards, Emmy reveals that she does not simply recollect these dreadful events, she re-experiences them, 'tangibly and in their true colour $[\ldots]$ the scene appears before her eyes as vividly as if it were real' (p. 55). Freud's response? To erase the images, he brushes her eyelids - several times. Through hypnosis, Freud touches Emmy. The touch in hypnosis and the touching through the twice-daily whole body massage begin to blend into one another. Thus, Emmy sometimes seems more responsive to revealing her feelings and thoughts while being massaged than while under hypnosis.

In the evening massage on Thursday 9 May, Emmy talks about the animals she has seen in an atlas her daughter's governess has given them. She is nervous, frightened. She stutters. The clicking has returned. Once again, Freud's response is to use hypnotic suggestion to overturn Emmy's reaction to the pictures. He instructs her to laugh at them and not to be afraid. On waking, she searches for the atlas, points to the pictures and laughs out loud. Unfortunately, the mood is broken by a visit from Dr Breuer, which induces anxiety in Emmy. Her stomach hurts. So, Freud relieves her symptoms by stroking her stomach. He then uses hypnosis to prevent the pains from returning. Perhaps, subtly and unconsciously, and contrary to her injunction not to touch, Emmy wishes Freud to touch her more and requires him to do so through recurrences of her bodily symptoms.

By the evening of 9 May, Emmy is happy and garrulous, displaying a sense of humour that Freud does not anticipate. She informs Freud that she had intended to give up her treatment with Dr Breuer (and consequently, therefore, with Freud), as she did not expect it to yield results. She was looking for a polite way to end it, and now a chance remark by Breuer had shown her how. Freud expresses surprise, yet silently defers. In this episode, we can detect a characteristic manipulation by Emmy - simultaneously pushing Freud away, while also drawing him further into her world. Freud has not yet learned to handle Emmy's unconscious communications, or his own.

In the evening's hypnotic session - in a move, albeit unconscious, that is hard not to see as combination both of revenge for her wish to leave his services and of desperation to maintain control over his valuable patient - Freud takes Emmy back into her experience of her insanity. After asking her, under hypnosis, what has given her 'a lasting fright' (p. 56), he pursues the point by asking when this fright was associated with insanity (p. 57). Emmy talks about her fear of asylums. In response, Freud uses suggestion. He attempts to 'correct her images of asylums' and assures Emmy that she will not be afraid of asylums again. Emmy relaxes. Then, she begins to detail more traumatic experiences: at 15, she finds her mother lying on the floor, having suffered a stroke; at 19, she found her mother dead, with a contorted expression on her face; in the same year, Emmy finds a toad under a stone and she cannot speak for hours.

On the morning of 10 May, Emmy has her first bran bath (rather than a warm bath), which was commonly used for skin irritations. The bath annoys Emmy. 
During the massage, Emmy says 'she still feels badly about having betrayed Dr Breuer yesterday' (p. 57). Freud's response is intriguing:

I tell a white lie to appease her, saying that I knew about it all along; at this her agitation (clicking, facial contraction) ceases.

The lie may be white, but it is nonetheless a lie. Freud is using both unconscious and conscious means, through suggestion and lies, to manipulate his patient into a happier frame of mind. Arguably, this is not treatment, but expediency. The white lie reveals that Freud needs Emmy to think that he knows more than he does, covertly giving the impression that he is unperturbed by the possibility that she might end her treatment with Dr Breuer (and therefore with him); Freud is also seeking to appease Emmy by showing that he is in control and that the treatment is working. In some form, Freud needs to seduce Emmy just as much as Emmy needs to seduce Freud. And it is easy to see the frequent massages in this light. Thus, Emmy's instruction 'Don't touch me!' has been wilfully converted into its opposite: 'Touch me!', with this unspoken injunction representing an unconscious accommodation between the desires and wishes of Emmy and Freud. The protective formula - seemingly fixed at the beginning of treatment, seemingly directed simultaneously at a memory and, perhaps simultaneously, at her Doctor Freud - is turned over and over-turned, in an unconscious negotiation of hand and voice, both his and hers.

In the hypnotic session that follows the massage, Freud investigates the meaning of her protective formula. Emmy says that the injunction to 'Keep Still' is designed to prevent things from getting worse. If she keeps still, and all those around her keep still, then the animal figures that she hallucinates will not attack her. 'Don't touch me' is associated with the illnesses of loved ones. For example, when she was 19, a brother became very ill. In his delirium, he would grab her arm. Moreover, when Emmy was 28, her small daughter (probably Mentona, who would have been 2 years old) became ill and would grab her so tightly that Emmy felt she was suffocating.

Intriguingly, Emmy's reasons for 'Don't say anything' are not explicitly reported in the case study, although there are hints at the need for silence in Emmy's response to the need for absolute stillness. The silence and stillness of those around her may be necessary for saving Emmy from being attacked and eaten by her fearful animal figures. It is pure speculation as to why this omission might be (whether in the hypnotic session or in Freud's writing up), but it is curious that it is the injunction most closely associated with 'the talking cure' that is omitted. Even so, Freud's response is, by now, predictable: he uses suggestion to remove the fear that Emmy's traumatic experiences might reoccur. In doing so, Freud not only lightens Emmy's mood, he also removes the need for her to use her protective formula, which now (more or less) disappears. 
We can observe that, at this point, Emmy appears to have replaced one protective formula with another, Freud. Yet Emmy's new found dependence soon gives way to her attempts to take control of her doctor. In the evening's hypnotic session, it is Emmy that tells Freud where they should start. They return, once again, to the theme of 'Don't touch me' (p. 59). Emmy produces yet more traumatic experiences and recurrent fears - which, once again, Freud seeks to erase through suggestion (p. 61). Freud assures Emmy that this process of identifying the sources of sadness and fear, and then erasing either the memory or the affect associated with it, is having success. Emmy, however, does not respond as Freud expects or hopes.

By the morning of 12 May, she is anxious, having slept badly. During the massage, however, she becomes more cheerful. In the hypnotic session, she talks about the nightmares she had in the night. This leads Emmy to talk about other fearful experiences with animals, including a mouse and a toad. The reappearance of Emmy's animal fears casts Freud into doubt: evidently, suggestion has not erased the affect associated with mice and toads, instead the affect has shifted to other memories. Freud turns the conversation towards Emmy's stomach pains (for which, the treatment had been massage). Emmy resists. Emmy sullenly tells Freud that he

should not always ask her where such and such a thing came from, but should let her tell [him] what she had to say.

Freud agrees. There is a turning point here. The injunction 'Don't say anything' is mute, but sullenly speaks: Freud is to interrogate less and listen more. Anna O. may have observed that (Breuer's) psychotherapy was a 'talking cure' (Breuer, 1895 , p. 34), but Emmy demonstrates she wants something more akin to a 'listening cure'. Do not say anything! The cure is for Emmy to talk, but crucially Freud has to pay attention to what she has to say - but what she has to say is being communicated through more than talk. It is a crucial lesson, which Freud is intuitively beginning to learn. But not yet put into practice.

By 14 May, Freud observes: 'Her talking things through prior to the hypnosis is becoming increasingly important' (p. 65). As we have observed, Emmy often prefers talking about her feelings and thoughts while being massaged. During the massage on the morning of 15 May, Emmy 'recounts some loosely connected stories, which may have been true - such as the story of the toad'. For Freud, this shows the kinds of associations that flow through Emmy's mind when she experiences a sense of unease. Such 'free associations' and their dream-like quality will, of course, become the stock in trade of psychoanalysis. Right now, however, Freud is concerned to solicit ever more stories connected with her symptoms, whether during massage or during hypnosis. Further, Freud is attempting to reveal the ways that Emmy's symptoms are connected to her experiences and reminiscences. 
Emmy, however, is not convinced that this is working. Freud himself becomes increasingly desperate in his use of suggestion, both as means to wipe out the memories associated with her symptoms, and also as a means to prevent the affect associated with the memories from breaking cover in the guise of new symptoms. In response to the fears Emmy expresses in the evening hypnotic session, Freud does not simply make a suggestion or seed an idea. Instead, he unambiguously lays down the law:

I forbid her this need to be afraid when there is no reason for it. She promises to refrain from doing so, 'because you ask me to'.

In response to Freud's command, Emmy makes a promise: a personal promise, on his behalf. The effect is to make all of Freud's treatments, suggestions and orders conditional upon Emmy's co-operation and consent. Emmy puts Freud back in his place. Once again, Emmy is teacher: the talking cure enables the patient to bring up hidden or repressed material, and it allows that material to be worked through in ways that alters its affect and its impact on the patient's symptoms - but only at the patient's discretion. Yet, despite Emmy's promises, Freud is forced to experiment with alternative techniques, as he reaches the limits of suggestion.

On 16 May, the massage and hypnosis sessions fail to alleviate pains that Emmy is experiencing in her face, arms and legs. Freud applies a faradic brush to Emmy's leg. The use of electromagnetism was common in medical practice in the 1880s and 1890s (Shorter, 1989, p. 161). Indeed, Charcot used a series of electromagnetic devices in his treatment of hysterics, which Freud witnessed during his visit to Salpêtrière Hospital only 4 or so years previously (see Didi-Huberman, 1982 [2003]). We can assume that it does not help, as Freud does not report the results, nor does he report its use again. By the evening, Emmy is once again terrified: fears criss-cross her mind and she is unable to distinguish past events from current ones. Freud persists with hypnosis and suggestion, once again forbidding Emmy from being afraid. Yet her horrors continue: terrors once associated with mice and toads become terrors associated worms and bats. Freud reassures her, yet again, that she is getting better and that the methods are working. Perhaps remarkably, Emmy's mood lifts. So, although her right leg has not responded to treatment, Emmy feels her pains have diminished and she sleeps well that night.

The daily regimen of hypnosis and massage has begun to yield positive results. Freud and Emmy form a desperate alliance in service of her better health. Two days later, Saturday 18 May, Freud observes that he had witnessed 'the last serious disturbance in Frau Emmy v. N.'s condition' (p. 72). As Emmy was not reporting any symptoms, Freud notes that

the hypnoses soon ceased to be productive and were mostly used by me to impart precepts which were meant to remain forever present in her 
thoughts and protect her from lapsing into a similar condition once back home again.

Or, put another way, Freud continues his attempts to permanently replace Emmy's protective formula with his own. Although Freud and Emmy are allied in their desire to change the passionate forms of her fears (such as the animal phobias, the pains in her limbs and stomach, her twitches and contortions, her altered voice and so on), their strategies are out of joint. Freud's strategy relies on cutting the link between the seemingly originating fear and the emergent symptom. Yet, Emmy's fears, desires and their passionate forms are more dynamic, and more inventive, than his treatments. Thus, even as Freud attempts to cut off the affects associated with the passionate forms of Emmy's anxieties, the affects remain and continue to circulate and search for new passionate forms: mice and toads turn into worms and bats (and back again), pains shift from one part of the body to another (and back again). So, Freud's cure forever does not last. Seven months later, Emmy is ill again (p. 72). And Freud does not hesitate to point the finger of blame at Emmy herself:

By an act of will, as it were, she [...] reversed the effect of my treatment an straightaway lapsed back into the very condition of which I had relieved her.

In the rest of this article, we would like to make two basic observations. First, the course of Emmy's treatment and Freud's therapeutic interventions ought to be read as an unconscious communication involving the movement, transfer and circulation of affects. Indeed, in some ways, it is possible to read the course of the treatment as a (failed or unrequited) love affair, in which the pair of them seek, but fail, to seduce one another. He tries to unlock her defences and hold her with reason, while she wants a far more passionate embrace. Second, following on, the dynamics of unconscious communication in the case history are absolutely key to understanding the course of the symptoms and the treatment. Neither treatment nor symptoms somehow stand independent of one another.

There is a real power struggle between patient and doctor over the definition and performance - of their respective roles: the Hysteric who has countless, unnameable fears and problems; the Doctor who knows and cures. Yet each confound, confuse, and somewhat alarm, the other. Emmy complains of the 'storms in her head' (p. 73), while Freud finds himself constantly frustrated in his attempts to quell the storms in any lasting way. In particular, the struggle over Emmy's protective formula is not won (by either side), and this is important: not only does the meaning of the injunctions mutate and move between the pair, but also various alternative protective spells are put in their place. Let us reflect further on Emmy's protective formula, each part in turn. 


\section{'Oh Keep Still!': Arresting the Movement of Desire and Meaning}

In our rendering of the case study, we have emphasized the to-and-fro of the treatment. This takes various forms. The treatment itself goes through daily cycles of massage and hypnosis: from massage table to couch to table and back again, from touch-and-talk to talk-without-touch to touch-and-talk and so on. There is a cycling of success and failure, with Emmy's moods lifting, then dramatically falling. There is a less subtle to-and-fro involving not only consent and command, but also more subtly involving seduction and rejection. Emmy seduces, as much as Freud; Emmy draws Freud in, but then pushes him away; Freud comforts and caresses, but he is also aloof and forbidding. What is interesting to us, in this back-and-forth between the pair, is that Emmy's protective formula seeks the exact opposite of all this movement, communication and touching: motionlessness, silence and distance.

The contradiction between the manifest content of Emmy's formula and its paradoxical outcome, for us, begs a simple question: what is it, exactly, that Emmy needs protection from? One answer is, of course, her own desire - here, directed towards her new Doctor, Freud. Yet, unlike many of her other doctors, Freud is not to be seduced. Worse, Freud will not be swayed from seeking to assert his control over her. Continually thwarted, Emmy's desires are converted constantly into her physical symptoms, phobias and hallucinations. Laing is helpful here. He writes that a characteristic of the hysteric is that

his or her actions should be false, that they should be false, that they should be histrionic, dramatized. The hysteric, on the other hand, often insists that his feelings are real and genuine. It is we who feel they are unreal.

(Laing, 1961, p. 52)

For Laing, hysterics, whether they are male or female, enact their real feelings through the histrionic drama of their hysterical symptoms, because in fantasy they can have whatever sexual relationship they like and they avoid having to encounter a real relationship with all its accompanying deprivations and disappointments. The idealized romantic attachments of hysterics, lived out in the imagination rather than in life, take the place of actual sexual relationships. From this perspective, the hysterics in Breuer and Freud's Studies of Hysteria long for love. Yet, they are arrested by this longing, carried away by passionate forms that keep keeping them away from the reality of their desires. Indeed, the passionate forms of hysterical symptoms are easily seen as purely theatrical, as mere inventions (see Didi-Huberman, 1982 [2003]). Even so, there is a realness at stake in the hysteric's symptoms that goes beyond theatrics: arguably, what is at stake is Emmy's ability to feel authentic, to make her passionate forms a real part of her lived experience - especially in relation to others, whom she demands so much of. Yet Emmy constantly thwarts her own desire, as she determinedly 
refuses to allow Freud to uncover the reality of the passionate forms that she so desperately wants relief from:

My attempts to expose this complex of symptoms as a reminiscence are unsuccessful. I ask some questions with this end in view - when she was nursing her brother, who was delirious, did he ever grab her by the neck? to which the answer was 'No', she says that she does not know where these attacks come from.

Affect will not be tied down to an event, such that it can be cauterized or removed. Instead, affect proves remarkably mobile and evasive. Freud wants Emmy to remember her repressed ideas, so her passions can be forgotten. But Emmy refuses the uncoupling of events, affect and passionate forms, as this uncoupling requires her to think rather than feel. While Freud wants Emmy to come up with forgotten events, which can then be therapeutically manipulated, she wants him to hear, and acknowledge, her buried feelings and her intimate suffering. Her injunction 'Keep Still' reverses into its opposite: she wants Freud to be moved by her, not stay detached from her affectual storms. And when he refuses, she refuses him. No, she says.

With Emmy, Freud began by only wanting sensible stories - ones that were reasonable and could be worked through in a linear fashion with a beginning, middle and an end. Yet, Freud learns that Emmy's passionate forms to not have a beginning, middle or end. There is a storm of passionate forms, which circulate and mutate without a clear origin. Each origin is another story that invites other stories. Perplexingly, symptoms erupt and subside without evident links to the treatment; indeed, positive outcomes to treatment had a habit of quickly dissolving. Freud was learning from Emmy to be suspicious of both hypnosis and massage: less because they could not fully embed Emmy in the real, more because they could not match the dynamics of affect and passionate forms. From our perspective, affect cannot simply be thought of either as a field that emerges between bodies or as something that is beyond communication. Rather, affect is produced, circulated, dynamic, transferred, mobile, mutable and communicative. Freud understood that his patients' stories somehow corresponded with their symptoms. Yet, he also realized that the relationships between stories, symptoms and their affects touch upon, and are entangled with, one another in often devious and disguised ways - like a network of spies with more than one cover story.

\section{'Don't Touch Me!': Hypnosis, Affect and the Power to Command}

Despite her demand not to be touched, Emmy and Freud collude in the use and re-use of two forms of therapeutic touch: the whole body massage and hypnosis. 
While the whole body massage might has its own histories (following Bauch, 2011), it seems clear that it functions more like a hypnotic session in the course of Freud's treatment; and, indeed, under hypnosis Freud will caress Emmy in a variety of ways. In this case, the techniques of massage and hypnosis blur. Through touch, it seems, Freud is attempting to make some kind of visceral connection between the body, affects and their passionate forms, including ideas and symptoms. Yet the injunction not to touch is constantly obeyed and disobeyed through the course of the treatment. What is at stake in this injunction is the struggle over who controls the conduct of the treatment.

We can see how this happens over and over again with Emmy. Freud is constantly frustrated that hypnosis is not working, yet still believes in his authority and in his power to impose his (therapeutic) will upon his patient (see also Campbell, 2006). However, Emmy increasingly resists, gloomily challenging his authority. Freud responds by trying to prove to Emmy that his technique has therapeutic power. Significantly, in the course of this struggle, Freud covertly plays two tricks on Emmy, both use hypnosis to re-establish the power of the doctor over his patient.

The first trick occurs when Emmy, full of barely suppressed rage, tells him about a recent stay in a sanatorium and a doctor who, under hypnosis, has forced her to spell out the word TOAD. Emmy, we know, is terrified of toads. To banish this memory, Freud suggests that the town in which the sanatorium is located would now feel, to her, geographically remote and be half-forgotten:

It was at this point that I allowed myself what was the only - and in any case fairly harmless - abuse of the hypnosis of which I am guilty in the case of this patient: I used suggestion to play a trick on her. I reassured her that her stay in - tal, would seem so far removed and distant from her that she would not even be able to think of the name of the place, and that whenever she wanted to mention it she would hesitate between - berg, - tal, - wald and so on. This then did occur, and soon her uncertainty about the name was her only noticeable speech defect, until a remark of Dr Breuer's led me to release her from this compulsive paramnesia.

(p. 75, emphasis added)

At the very beginning of the treatment, it is Emmy who commands the Doctor: 'Keep Still! - Don't Say Anything! - Don't Touch Me!'. Drawing upon the authority of the doctor and the technique of hypnosis, Freud gradually asserts his will over Emmy's unconscious and against her resistance. Yet his trick is ambiguous: it shows his power to assert his will - and, also, to release the grip of his will - over Emmy. Yet, Emmy would be aware that a trick was being played. Later, Emmy forces Freud to install a post-hypnotic protective spell, preventing any future doctor from using hypnotic techniques upon her. Significantly, Emmy remains in control of this protective spell. Later still, Emmy 
requires Freud to release her from the unconscious protection against further hypnosis, in writing. About this, Freud says:

The last I heard of her (summer 1893) was a short note in which she asked me to permit another doctor to hypnotize her, as she was ill again and not able to come to Vienna. At first I did not understand why this needed my consent; then the memory came to me that in the year $1890 \mathrm{I}$ had, at her own request, protected her from being hypnotized by anyone else, so that she would not risk the distress of again coming under the control of a doctor whom she found unsympathetic, as she had done during the time at - berg (- tal, - wald). And so I relinquished my exclusive prerogative in writing.

The fairly harmless trick is far from harmless, not only does it haunt Freud, it rebounds against him - as Emmy's repressions strengthen and as she strengthens her resistances against his suggestions. Indeed, in the face of Emmy's increasing resistance to treatment, Freud deploys a second trick as he attempts to assert the power of the doctor to cure the patient even against their will.

Towards the end of the treatment, Freud notices that Emmy 'seemed unwilling to communicate under hypnosis' (p. 79). She complains of the large gaps in her memory 'especially the most important events', as a consequence of Freud's erasures. Indeed, Emmy tells Freud, while under hypnosis, that she will probably no longer obey his hypnotic suggestions in the way that she has done before. And so Freud decides to convince her otherwise, and to break her resistance, by showing her the unconscious power of hypnotic suggestion. He writes her a message and hands it to her. It reads:

At midday today you will pour me a glass of red wine as you did yesterday. As I raise the glass to my lips you will say, 'Oh please, pour me a glass too', and then when I reach for the bottle, you will call out, 'No, thank you, I would rather not after all'. At this, you will reach into your pocket and pull out the piece of paper on which these same words appear.

All this happens exactly as Freud envisages, and yet after this visit Emmy terminates the treatment and leaves. After all, Freud had always sought to avoid the full force of the vicissitudes of Emmy's passions and, consequently, left her increasingly dissatisfied with the treatment, irrespective of whether his tricks worked as proofs or as authority or as power or as cure. Hypnosis, then, left both doctor and patient without a happy ending. But Emmy had taught Freud well: the protective spell, 'Don't say anything!', would inform psychoanalysis, as Freud sought new means to receive and to pay attention to what his patients were saying (see also, Pile, 2010b). 


\section{'Don't Say Anything!': Talking and the Dynamics of Unconscious Communication.}

As we have heard, Emmy was keen to instruct Freud, telling him to question less and listen more. As Freud develops psychoanalysis, he implicitly takes Emmy's injunction not to say anything to heart. Away from the massage table, Freud (famously) moves beside the couch, physically detaching himself from the patient. Simultaneously, we can note, Freud also obeys Emmy's injunction not to touch. Thus, Freud is attempting both to register and to manage the unconscious transmission of affects in the clinical setting. Like a radio operator, he is trying to cut out the distracting static of communication by tuning his body to what is actually being communicated through the voice, consciously and unconsciously. In this model, Freud receives what the patient sends out. However, not only is the therapist also reacting to what is received, the therapist also transmits, just as the patient receives. Therapeutically, the key is to understand, and work with, the entanglements between unconscious communication and conscious expression.

Consequently, psychoanalytic debates about transference and counter-transference have emphasized the importance of the unconscious messages transmitted and received by patient and therapist, yet so often this unconscious communication is described as unidirectional. Thus, the analyst can receive the patient's projective identifications, or indeed initiate her/his own projections, as has described Ogden (1979). For Sandler, however, unconscious communication is acknowledged as being more of a conversation, with the analyst being unconsciously responsive outside of the roles or projections imposed on him/her (Sandler, 1976). And yet, even here, the radically open transfer of unconscious ideas and affects between therapist and patient remains under-acknowledged (see Campbell and Pile, 2010).

To really understand the nature of unconscious communication in the analytic session we have to stop seeing it as something that has to pass through conscious mental representation and language. In hysteria, for example, affects become separated from language, or the chain of signifiers that would seemingly abreact them. And yet we argue that the affects of the hysteric are not simply seeking an expression that will diffuse or wash them away. Rather, affects, and the symptoms which carry them, are seeking new forms. These new forms have the potential, not so much to abreact existing affects as to reconfigure affectual relationships into more mobile and exchangeable forms.

From this perspective, Lacan (1957 [1977]) was wrong to suggest that the unconscious is a language or is structured like a language. Rather, as Freud writes about hysteria and its relationship to symbols, 'it may be that [hysteria] has not taken linguistic usage as its model at all, but both hysteria and linguistic usage alike draw their material from a common source' (Freud, 1895b [2004], p. 184). In this view, words are like symptoms: a passionate form. Words and symptoms are structured, contra Lacan, by unconscious processes. They become the form 
through which passions are lived, yet in ways that do not simply speak the fears and desires that bring them into expression. Unlike the tells that give away a poker player's hidden thoughts, passionate forms pretend to be what they really are - like Emmy's stomach pains in search of a soothing massage, they are overdetermined, repetitious and falsely real.

Thus, verbalization in the talking cure that we call psychoanalysis is never just talk, it is always something that entrains and is entrained by affects. For Emmy, it is part of the events that make up her psychic life, her past and her present. And it is the movement between affects and ideas, or the stand-off or misalliance between affects and their possible forms, when it comes to hysteria, that creates and demonstrates the insufficiency of hypnosis. As Freud himself realized hypnosis on its own does nothing to lift repression, nor is it sufficient in mobilizing any lasting change. And this is, partly, because hypnotic therapy takes no account of the arts of defence, what André Green calls the 'work of the negative' (Green, 1993).

Emmy wants Freud to listen, to feel, to touch; she has little use for Freud's intelligent deconstruction of her signifying chains, she wants his passion. It is only through his love that she can associate and bring into the communication her buried longings and emotions. Although Freud tries to master her symptoms (mainly, by attempting to exterminate them), he can barely manage her passionate demands. Emmy's passions in this sense are more than either Freud or she can practically bear. Freud eventually recognizes that his thinking, rational ego cannot overpower Emmy's affects - as he realizes that his reassurances, prohibitions, counter suggestions and attempts to erase Emmy's unconscious memories and symptoms through hypnosis simply do not work. And they do not work because Emmy's symptoms disappear only to rise up again more vehemently than before. Thus, from our perspective, Freud abandons hypnosis not because it is not rational enough (as Chertok and Stengers, 1992, argue), but because it is too rational, too disconnected from the body, from affect, and from passionate forms.

Christopher Bollas argues that, with Emmy, Freud 'does not fathom the structure of the hysteric's transmissions: that of a self caught up in the stories of the other, bound to identify with them, and then to narrate and perform them' (2000, p. 54). For Bollas, Emmy's hysterical stories are evidence of how she is continuously locked into a performative acting out of the other's imaginary desire. Emmy wants to be what she imagines is Freud's passionate object, but this is at the expense of elaborating her own desire. Another way of saying this is to suggest that Emmy lacks a living form that can elaborate her passionate affects. Campbell (2013) has argued, along these lines, that hysterics' affects are in search of lived, communicative and maternal forms that will carry and elaborate their passion. Thus, it is not so much that Emmy simply performs an imaginary version of what she thinks Freud desires, it is rather that her affects are constantly in search of forms for passions that have hitherto been disconnected, by repression, from any form of expression. 
Although a repressed unconscious is the mystery that psychoanalysis is aimed at unlocking, it can only begin to do this, first, by unconsciously receiving the patient's unintended communications (see also Campbell and Pile, 2010). Thus, it is not only through the symptoms that repressed affect can be revealed, it is also through unconscious communication. Symptoms cannot be wished away by the magic of hypnosis, nor by the force of the ego's will. It is only by allowing the symptom its energetic and corporeal force, its ability to unconsciously communicate, that affects can finally be allowed their needed circulation and exchange in relation to others. The mistake of hypnosis, then, is to seek to disconnect affects and their passionate forms, rather than, instead, seeking new forms for the passions. In this light, Emmy's mistake was not that she created a protective formula for herself, but that she became thoroughly caught up in it - and even entangled others in it, too, including Freud.

\section{Conclusion: Hysteria and Transference as the Re-Configuration of Affect}

Hysteria manifests itself as the symptoms of a trauma, associated with a complex of secret and prohibited desires/fears. A symptom may lead directly back to the trauma, but this unfortunately is not the end of matters. When Freud confronts Emmy with a traumatic situation (such as the death of close relatives), her reaction is to proliferate her hysterical symptoms. The associative paths between forms and affects are tangled and mutable. Yet, her symptoms 'fix' her fears and anxieties, in part by moving them out of reach of Freud's intervention. Emmy is able to repeat and proliferate, again and again, her symptoms, as Freud struggles to keep up with what is going on. Viewed in this way, hysterical symptoms are an unconscious communication that has become blocked or diverted: partly, because symptoms are experienced and received as too corporeal, too painful and too excessive. Keep still! Do not say anything! Do not touch me! Symptoms, in some accounts of psychoanalysis, have to cured, sublimated and put back inside of an ego that is mentally and consciously in control. Yet, symptoms are also arguably the most hopeful signs in therapy, because they are glued to unconscious passions that have escaped from the repressed unconscious and are in search of more communicative forms.

In the case of Emmy, her symptoms are paradoxical: they are the evidence of her immobilizing fears, the unbearability of being touched and of the impossibility of representation; and yet they are also the very bodily materials through which her unconscious touches and moves others. Thus, symptoms become definite forms through which communication can take place. Through her phobias and pains, Emmy draws Freud close, explicitly (sullenly) hoping that he will open himself up to what she is feeling. Not that she knows what she wants. Not that Freud knows what new forms her passions might or should take. Not 
that either know how to move Emmy's passionate forms into new formations. Emmy is ultimately stuck, repeating 'old' passionate forms, unable to recall or face the affects that are embroiled in them, yet paradoxically unable to disconnect those affects and embrace new forms.

The problem, for Freud, is that the use of hypnosis assumes that the word for Emmy's fears is directly linked to the fear itself: eliminate the word and you eliminate the fear associated with the word and, therefore, you eliminate the symptom. Forget the toad. Forget the fear associated with the toad. Without the fear, Emmy would be cured. Yet, it did neither Freud nor Emmy any good to assume that there was a direct connection between words (toad, mice), their associated emotions (disgust, horror) and their bodily affects (clenched jaw, frozen in fear and crooked fingers). This problem challenges attempts to privilege, as Wetherell does, discourse as a means for accessing affect: not only are passionate forms carried through more than discourse, affects are entangled in the production of passionate forms in less than straight-forward ways. Yet, nor would it have helped Freud or Emmy to assume that the affects that manifested themselves between them (whether through massage, through verbal injunctions, through their struggles over the therapeutic determination of meaning or through hypnotic suggestion) were somehow pre-social, uncommunicative, and incapable of finding forms. This observation challenges attempts, such as Massumi's, to guarantee the place and significance of the affect by locating them in a different order than their representational forms. Yet, while Massumi wishes to preserve the possible by saving it from representation, for Emmy, and later for Freud, the possible requires representation. The possible is not forestalled by passionate forms, but becomes possible through them.

What Emmy tells us is that the problem of subjectivity will not be solved by presuming that her subjectivity is subjectless or presocial, nor that the relationship between affect, the body and the meaning of words themselves can be plainly expressed in language. Terms such as hysterical symptoms, passionate forms and, indeed, threshold phenomena stand in midst of the entanglements between affects, the body, the social and the forms through which affects and meanings emerge. The problem is that subjectivity is itself an entangled, passionate phenomena - just as are affects and language. Freud found that Emmy's passionate forms (fingers, voice and phobias) could not be severed from the mess of affects and ideas that they were forms for. Then again, through listening to her words, Freud was able to follow pathways that led to the stories behind the stories, to a sense of how these passionate forms might have emerged and how they might have become fixed and repeated, instinctive even. But listening is achieved through more than thinking about what is said, Freud also uses his hands - just as Emmy uses hers; indeed, she uses both hers and Freud's. Passionate forms, consequently, have threads that reach to the repressed unconscious, to a receptive and communicative unconscious, through the body and into the social. 
In the treatment of Emma, Freud wants to expel the TOAD using the magic of suggestion. Emmy's toads are the unacceptable face of her passion, yet they need the right spell of transformation, not banishment. The right spell is not the magical realization of her wishes, nor some rationalized grammar of emotional wellbeing, but rather the possibility that unconscious communication might produce new forms for the passions. The problem of subjectivity, for Freud, turns around the question of tracking affect, through Emmy's body and words, and of seeking new, less painful and damaging, forms for her passions. Affects are never just directly circulated between bodies with no mediation; they are always en route between internal and external worlds, between the past and the present. As such, affects can move between the first primitive forms of passions to more flexible shapes and spaces provided by others.

Protective spells, as much as the clinical setting, can provide a safe haven. And for Freud and Emmy that is what the spells and suggestions magically achieved, they kept both parties safe and the same: mad-woman and doctor repeating the same fantasy, again and again. Transforming fantasies of love and cure into 'the real thing' cannot be achieved through spells or tricks. And perhaps the hardest lesson that Freud was beginning to learn, and of course kept failing to remember, was that toads, however loathsome, are only the negative side of Emmy's desire. Emmy's toads could not be hypnotically squashed any more than they could be transformed by simply talking about them. But, as a communicative form for her passions, they could be transformed, but only if Freud was able to unconsciously receive them, and both together turn them into the right kind of prince.

\section{Acknowledgements}

We would like to thank the referees and the editors for their critical, yet insightful and thought-provoking, comments during the production of this article.

\section{About the Authors}

Jan Campbell is a practicing psychotherapist in Brighton, United Kingdom. Her writing is concerned with psychoanalysis in relation to a politics of cultural theory, feminism, autobiography, film and clinical practice. In her latest book Freudian Passions: psychoanalysis, form and literature (2006), she re-reads Freud's thinking on sexuality and transference to rethink the forms that our passions take, especially in language and literature. Her current research is on Freud, unconscious communication, and the body. 
Steve Pile has published on issues concerning place and the politics of identity. He is author of Real Cities: modernity, space and the phantasmagorias of city life (2005) and The Body and The City: psychoanalysis, subjectivity and space (1996). His many collaborative projects include the collection, Psychoanalytic Geographies (2014), edited with Paul Kingsbury. He is currently working on early Freudian psychoanalysis and geographies of the body.

\section{References}

Appignanesi, L. and Forrester, J. (2005) Freud's Women. 2nd edn. London: Phoenix.

Bauch, N. (2011) The extensible digestive system: Biotechnology at the battle creek sanitarium, 1890-1900. Cultural Geographies 18(2): 209-229.

Blackman, L. (2012) Immaterial Bodies: Affect, Embodiment, Mediation. London: Sage.

Bollas, C. (2000) Hysteria. London: Routledge.

Bourdieu, P. (1984) Distinction: A Social Critique of the Judgement of Taste. Cambridge, MA: Harvard University Press.

Breuer, J. (1895) Fräulein Anna O. In: S. Freud and J. Breuer (eds.) Studies in Hysteria. 2004. Harmondsworth: Penguin Modern Classics, pp. 25-50.

Bromberg, P.M. (2001) Hysteria, dissociation, and cure: Emmy von N. revisited. In: M. Dimen and A. Harris (eds.) Storms in her Head: Freud and the Construction of Hysteria. New York: Other Press, pp. 121-142.

Campbell, J. and Pile, S. (2010) Telepathy and its vicissitudes: Freud, thought transference and the hidden lives of the (repressed and non-repressed) unconscious. Subjectivity 3(4): 403-425.

Campbell, J. and Pile, S. (2011) Space travels of the wolfman: Phobia and its worlds. Psychoanalysis and History 13(1): 69-89.

Campbell, J. (2006) Psychoanalysis and the Time of Life: Durations of the Unconscious Self. London: Routledge.

Campbell, J. (2013) Freudian Passions: Psychoanalysis, Form and Literature. London: Karnac Books.

Clough, P. (2010) The affective turn: Political economy, biomedia and bodies. In: M. Gregg and G.J. Seigworth (eds.) The Affect Theory Reader. Durham, NC: Duke University Press.

Chertok, L. and Stengers, I. (1992) A Critique of Psychoanalytic Reason: Hypnosis as a Scientific Problem from Lavoisier to Lacan. Stanford: Stanford University Press.

Didi-Huberman, G. (1982 [2003]) Invention of Hysteria: Charcot and the Photographic Iconography of the Salpêtrière. Cambridge, MA: The MIT Press.

Ellenberger, H. (1977 [1993]) The story of 'Emmy von N.': A critical study with new documents. In: M.S. Micale (ed.) Beyond the Unconscious: Essays of Henri F. Ellenberger in the History of Psychiatry. Princeton, NJ: Princeton University Press, pp. 273-290.

Freud, S. (1895a) Frau Emmy von N., age 40, from Livonia. In: S. Freud and J. Breuer (eds.) Studies in Hysteria. 2004. Harmondsworth: Penguin Modern Classics, pp. 51-108.

Freud, S. (1895b [2004]) Fraulein Elizabeth von R. In: S. Freud and J. Breuer (eds.) Studies in Hysteria. London: Penguin, pp. 139-186. 
Goffman, E. (1981) Forms of Talk. Philadelphia, PA: University of Pennsylvania Press.

Goldstein, J.E. (2001) The case history in historical perspective: Nanette Leroux and Emmy von N. In: M. Dimen and A. Harris (eds.) Storms in her Head: Freud and the Construction of Hysteria. New York: Other Press, pp. 143-166.

Hemmings, S. (2005) Invoking affect: Cultural theory and the ontological turn. Cultural Studies 19(5): 548-567.

Lacan, J. (1957 [1977]) (ed.) The agency of the letter in the unconscious, or reason since Freud. In: Écrits: A Selection. London: Tavistock Publications, pp. 146-178.

Laing, R.D. (1961) The Self and Others. London: Penguin Books.

Leys, R. (2011) The turn to affect: A critique. Critical Inquiry 37(3): 434-472.

Massumi, B. (2002) Parables for the Virtual: Movement, affect, Sensation. Durham, NC: Duke University Press.

Ogden, T. (1979) On projective identification. International Journal of Psycho-Analysis 60: 357-373.

Pile, S. (2010a) Affect and emotion in recent human geography. Transactions of the Institute of British Geographers 35: 5-20.

Pile, S. (2010b) Intimate distance: The unconscious dimension of the rapport between researcher and researched. Professional Geographer 62(4): 483-495.

Pile, S. (2014) Beastly minds: A topological twist in the rethinking of the human in nonhuman geographies using two of Freud's case studies, Emmy von N. and the Wolfman. Transactions of the Institute of British Geographers 39: 224-236.

Roth, M.S. (2001) Falling into history: Freud's case of Frau Emmy von N. In: M. Dimen and A. Harris (eds.) Storms in Her Head: Freud and the Construction of Hysteria. New York: Other Press, pp. 167-184.

Schwartz (2001) Eroticism and representation: The epistemology of sex in light of the case of Frau Emmy von N. In: M. Dimen and A. Harris (eds.) Storms in her Head: Freud and the Construction of Hysteria. New York: Other Press, pp. 185-200.

Shorter, E. (1989) Women and jews in a private nervous clinic in late nineteenth-century Vienna. Medical History 33(2): 149-183.

Tögel, C. (1999) 'My bad diagnostic error': Once more about Freud and Emmy v. N. (Fanny Moser). International Journal of Psycho-Analysis 80: 1165-1173.

Wetherell, M. (2012) Affect and Emotion: A New Social Science Understanding. London: Sage.

Williams, R. (1958) Marxism and Literature. Oxford: Oxford University Press.

Winter, A. (1998) Mesmerized: Power of Mind in Victorian Britain. Chicago, IL: University of Chicago Press. 